\title{
MBOUKOU Serge, « Espèces de lieux. Non-lieux, hyper-lieux et tiers- lieux : questions sur le devenir et la pertinence d'une ville de l'avenir en tant que lieu expérientiel » in Mutations, École nationale supérieure d'architecture de Nancy, 2016-2018, pp. 27-45.
}

\section{Benoît Goetz}

\section{(2) OpenEdition Journals}

\section{Édition électronique}

URL : http://journals.openedition.org/leportique/3650

DOI : $10.4000 /$ leportique.3650

ISSN : $1777-5280$

\section{Éditeur}

Association "Les Amis du Portique"

\section{Édition imprimée}

Date de publication : 1 septembre 2019

Pagination : $320-322$

ISBN : 978-2-916332-40-6

ISSN : $1283-8594$

\section{Référence électronique}

Benoît Goetz, « MBOUKOU Serge, «Espèces de lieux. Non-lieux, hyper-lieux et tiers- lieux : questions sur le devenir et la pertinence d'une ville de l'avenir en tant que lieu expérientiel » in Mutations, École nationale supérieure d'architecture de Nancy, 2016-2018, pp. 27-45. », Le Portique [En ligne], 43-44 | 2019, document 23, mis en ligne le 01 septembre 2019, consulté le 25 mars 2021. URL : http:// journals.openedition.org/leportique/3650; DOI : https://doi.org/10.4000/leportique.3650

Ce document a été généré automatiquement le 25 mars 2021.

Tous droits réservés 


\title{
MBOUKOU Serge, « Espèces de lieux. Non-lieux, hyper-lieux et tiers- lieux : questions sur le devenir et la pertinence d'une ville de l'avenir en tant que lieu expérientiel » in Mutations, École nationale supérieure d'architecture de Nancy, 2016-2018, pp. 27-45.
}

\author{
Benoît Goetz
}

\begin{abstract}
Une étrange panique s'empare des anthropologues de l'espace. Tout se passe comme si glissait sous leurs pieds une notion clef leur permettant de parcourir avec assurance leurs terrains : le notion de lieu. Concept antique et vénérable qui, semble-t-il, est entré en crise profonde aujourd'hui. Le symptôme de cette crise est le « travail du concept » à l'œuvre ces dernières décennies. Non lieux, hyper-lieux, tiers-lieux : ces vocables font signe à la fois vers une mutation et une résistance de la notion. Les lieux sont entrés en flottaison, comme s'ils avaient été désancrés et abandonnés à l'errance. Et l'espace de jeu où se joue cette aventure n'est autre que la ville, ce qui arrive à la ville, et ce qui vient après la ville.
\end{abstract}

Dans un article important, Serge Mboukou s'aventure courageusement sur ce terrain mouvant. D'abord en lecteur de Marc Augé et de Michel Lussault, il montre la pertinence des concepts de non-lieux et d'hyper-lieux qui, sous leur apparente contradiction, enregistrent une même main mise sur l'espace réel par les écrans des nouvelles technologies. L'habitant des villes n'est plus là. Il est là sans être là, ici et ailleurs. Il est partout et nulle part. Ubiquité qui peut être enthousiasmante. L'euphorie 
face à ce qu'annonce ces mutations contemporaines laissent Serge Mboukou sceptique. Il préfère faire un sort à la notion de tiers-lieux empruntée à Antoine Burret (Tiers-lieux et plus si affinité, Limoges, Éd. Fyp, 2015). Et il développe l'idée qui est la sienne de «lieu expérientiel »: " Fidèle à sa propre histoire qui la constitue comme milieu de questionnement, d'invention, de critique, d'abstraction et de production de signes, la ville, comme milieu fécond ouvre, avec le tiers lieu, une nouvelle page de son devenir possible. Elle peut être envisagée comme un tiers-lieu total en devenir » (p. 43). Un lieu expérientiel serait celui où s'invente des possibilités de vie, des "contre-façons " (Michel de $\left(\mathrm{Crteau}^{1}\right)$ par rapport aux modes de vie qui s'imposent. Des lieux de conversation (mot que Serge Mboukou affectionne). Bref l'idée est que les conditions de localisation ne peuvent jamais s'imposer de manière univoque. "N'accuse pas le lieu » disait un ancien proverbe. Nous restons libre d'inventer des manières d'être à l'espace, des envers et des endroits, lieux ou pas. En fait cette notion de lieu devient par trop lourde. Et il est inutile de le surcharger davantage. Toujours encore le lieu nous rattrape. Parce qu'il est impossible de s'en débarrasser tant que nous resterons des " être-le-là ». Pour longtemps, du moins on peut l'espérer.

\section{NOTES}

1. Rappelons que Serge Mboukou est l'auteur dans cette même revue en 1995 de l'article : « Entre stratégie et tactique. Figures et typologie des usagers de l'espace à partir de Michel de Certeau »; et, en 2008 de l'ouvrage : Michel de Certeau, l'intelligence de la sensibilité. Anthropologie, expérience et énonciation, Les Cahiers du Portique, 2009. 